\title{
Microwave synthesis of manganese-ion-doped zinc sulfide nano-phosphors using a novel monomer
}

\author{
Chung-Hsin Lu*, Baibaswata Bhattacharjee ${ }^{1}$, Shih-Yen Chen \\ Electronic and Electro-optical Ceramics Laboratory, Department of Chemical Engineering, National Taiwan University, Taipei, Taiwan, ROC
}

\section{A R T I C L E I N F O}

\section{Article history:}

Received 23 April 2008

Received in revised form 5 August 2008

Accepted 13 August 2008

Available online $\mathrm{xxx}$

\section{Keywords:}

Nano-particles

$\mathrm{ZnS}: \mathrm{Mn}^{2+}$

Luminescence

Microwave synthesis

\begin{abstract}
A B S T R A C T
$\mathrm{ZnS}: \mathrm{Mn}^{2+}$ nano-phosphors are synthesized via a microwave irradiation technique using zinc 2ethylhexanoate as a novel zinc precursor. The developed process produces $\mathrm{ZnS}: \mathrm{Mn}^{2+}$ nano-particles having in situ capping of 2-ethylhexanoic acid on the surface, resulting in high luminescence intensity due to effective surface passivation. Surface characterization of the nano-particles indicates that 2-ethylhexanoic acid is chemisorbed as carboxylate onto the surface of $\mathrm{ZnS}: \mathrm{Mn}^{2+}$ nano-particles and the two oxygen atoms in the carboxylate are coordinated symmetrically to the $\mathrm{Zn}$ atoms, leading to the formation of the covalent $\mathrm{Zn}-\mathrm{O}$ bond. The anion bound onto the nano-particle surface prevents particle agglomeration due to electrostatic repulsion between two adjacent particles. Electron spin resonance (ESR) spectrum showed a hyperfine sextet revealing the fact that $\mathrm{Mn}^{2+}$ in $\mathrm{ZnS}$ was present as dispersed $\mathrm{Mn}^{2+}$ impurities rather than $\mathrm{Mn}^{2+}$ clusters, which would produce broad resonance without splitting. The samples showed bright yellow-orange luminescence at about $585 \mathrm{~nm}$, characteristic of ${ }^{4} \mathrm{~T}_{1}$ (excited) $\rightarrow{ }^{6} \mathrm{~A}_{1}$ (ground) transition of $\mathrm{Mn}^{2+}$ ion at $\mathrm{T}_{\mathrm{d}}$ symmetry in $\mathrm{ZnS}$.
\end{abstract}

(c) 2008 Elsevier B.V. All rights reserved.

\section{Introduction}

Semiconductor nano-particles have been emerged as an attractive field of theoretical as well as applied research of late and investigated extensively in recent years [1-6]. Nano-materials can be described as the intermediate state of matter between individual molecule and bulk materials [1]. Transition from bulk materials to nano-particles results the size-dependent material properties as a consequence of quantum size effect [2]. The small size and controllable optical property of certain semiconductors make them interesting for applications in the fields of optoelectronics [4] catalysis [5] and fluorescence microscopy [6]. Particles of very small sizes show unique physical properties. With a decrease in particle size, an extremely high surface to volume ratio is obtained. This leads to an increase in surface specific active sites for chemical reactions and photon absorption to enhance the reaction and absorption efficiency. The enhanced surface area increases surface states, which changes electron and hole activities and affects the chemical reaction dynamics. Nano-particles can also induce the possibility of indirect electron transitions at the crystal boundaries, realizing essential light absorption enhancement.

\footnotetext{
* Corresponding author.

E-mail address: chlu@ntu.edu.tw (C.-H. Lu).

1 Permanent Address: Department of Physics, Ramananda College, Bishnupur, Bankura 722 122, West Bengal, India.
}

ZnS nano-particles are used as phosphors for display devices. ZnS doped with manganese-ions (yellow-orange emission at around $590 \mathrm{~nm}$ ) [7,8], copper-ions (green emission at around $510 \mathrm{~nm}$ ) $[9,10]$ and silver-ions (blue emission at around $440 \mathrm{~nm}$ ) [11] have a potential application in field emission devices (FED) [12]. Organometallic methods for the synthesis of nano-particles have been described by Bhargava et al. [7] and Gallagher et al. [13] Yu et al. [14] synthesized ZnS: $\mathrm{Mn}^{2+}$ nano-particles in methanol using sodium polyphosphate as the capping agent. Recently, sonochemical synthesis [15] of $\mathrm{ZnS}: \mathrm{Mn}^{2+}$ nano-particles has also been reported. Precipitations from homogeneous solutions have been reported, where it was found that the particle size was a function of the nature of the associated anions [16,17].

Although $\mathrm{ZnS}: \mathrm{Mn}^{2+}$ nano-particles have been prepared via different processes in the past few years, the used synthesis and capping processes usually require complicated procedures. In order to simplify the process, we adopted the microwave process for preparing $\mathrm{ZnS}: \mathrm{Mn}^{2+}$. This process can synthesize $\mathrm{ZnS}: \mathrm{Mn}^{2+}$ and form the capped layer in one step. In addition, in the conventional synthesis and drying processes, the formed $\mathrm{ZnS}: \mathrm{Mn}^{2+}$ nano-particles tend to agglomerate together. For solving this problem, we used zinc 2-ethylhexanoate as a new zinc precursor. This precursor can produce in situ capping of 2-ethylhexanoic acid on the surface, thereby preventing particle agglomeration due to electrostatic repulsion, and resulting in improvement in luminescent properties. The chemical interaction of the carboxylic acid group with the $\mathrm{ZnS}: \mathrm{Mn}^{2+}$ nano-particle was investigated using Fourier 
transform infrared spectroscopy (FTIR) and X-ray photoelectron spectroscopy (XPS). The luminescent properties of the prepared nano-particles were also studied in details.

\section{Experimental}

Zinc 2-ethylhexanoate $\left[\mathrm{CH}_{3}\left(\mathrm{CH}_{2}\right)_{3} \mathrm{CH}\left(\mathrm{C}_{2} \mathrm{H}_{5}\right) \mathrm{COO}_{2} \mathrm{Zn}\right]$ and thiourea $\left(\mathrm{NH}_{2} \mathrm{CSNH}_{2}\right)$ were dissolved in a mixture of methanol and de-ionized water (volume ratio 5:1) at a molar ratio of $\mathrm{Zn} /$ sulfur $1-10$. Stoichiometrically excess amount of sulfur was used to ensure the completion of reaction. One atomic \% $\mathrm{Mn}^{2+}$ doping was carried out through dissolving manganese acetate in the solution. After that, the solution was first stirred at room temperature for $15 \mathrm{~min}$ and then sonicated for $90 \mathrm{~min}$. Ultrasonic irradiation was accomplished with a high-intensity ultrasonic bath (Branson 3510). After sonication, the solution was transferred to double walled microwave digestion vessel of volume $100 \mathrm{ml}$, filling up to $60 \%$ of its volume. A high performance microwave digestion unit (MLS 1200 Mega) operated at the frequency $2450 \mathrm{MHz}$ was used for microwave synthesis. The microwave power and synthesis temperature were set at $200 \mathrm{~W}$ and $150{ }^{\circ} \mathrm{C}$, respectively. The microwave generator was programmed to shut down for maintaining the system at the set temperature. The pressure attained at the synthesis was $80.5 \mathrm{psi}$ as measured using a pressure sensor attached within the reference vessel. Once the reaction was completed, the solution was cooled to room temperature. The precipitates were centrifuged, washed with de-ionized water, ethanol and acetone for several times and dried at $70^{\circ} \mathrm{C}$ in a vacuum oven for the characterization process.

Transmission electron microscopy (TEM) was performed using a Hitachi $\mathrm{H}-$ 7100 microscope operated at the voltage of $100 \mathrm{kV}$. Powder dispersed in ethanol was carefully placed on the carbon coated $\mathrm{Cu}$ grid for TEM study. A particle size analyzer (Nano-S, Malven, Worcedtershire, UK) was used to measure the size distribution histogram using methanol as the solvent. An X-ray diffraction (XRD) study was performed in a MAC M03 XHF diffractometer using Ni filtered $\mathrm{Cu} \mathrm{K} \alpha$ radiation $(\lambda=0.154056 \mathrm{~nm})$ as X-ray source at $40 \mathrm{kV}, 30 \mathrm{~mA}$. Fourier transformed infrared (FTIR) study was performed on Thermo Nicolet NEXUS 470 spectrometer. X-ray photoelectron spectroscopic (XPS) measurements were performed on a VG Microtech (MT-500) machine using Al K $\alpha$ radiation. Diffuse reflectance spectra were recorded using a spectrophotometer (Hitachi-U3410) at room temperature with a resolution of $\lambda \sim 0.07 \mathrm{~nm}$ along with a photometric accuracy of $\pm 0.3 \%$. Electron spin resonance (ESR) resonance spectra were recorded using a Bruker EMX X band spectrometer. The microwave frequency was $9.76 \mathrm{GHz}$ and a $100 \mathrm{kHz}$ field modulation was used. The photoluminescence excitation (PLE) and photoluminescence emission (PL) measurements were performed in a Hitachi F-4500 fluorescence spectrophotometer at room temperature using a Xe lamp as the excitation source.

\section{Results and discussion}

\subsection{Microstructures of $\mathrm{ZnS}: \mathrm{Mn}^{2+}$ nano-particles}

Fig. 1(a) shows the TEM of ZnS: $\mathrm{Mn}^{2+}$ nano-particles with the corresponding diffraction pattern in inset. Presence of fine $\mathrm{ZnS}: \mathrm{Mn}^{2+}$ nano-particles is clearly visible in the TEM picture (Fig. 1(a)). The diffraction pattern of the sample consists of a central halo with concentric broad rings. The rings correspond to the reflections from (111), (220) and (311) planes confirming the cubic crystallographic structure of the $\mathrm{ZnS}$ nano-particles. The average size $\left(D_{\mathrm{av}}\right)$ of the nano-crystallites determined from TEM is around $3 \mathrm{~nm}$ $( \pm 0.5 \mathrm{~nm})$. Particle size analysis (PSA) data shows (Fig. 1(b)) narrow size distribution of the particles with $D_{\mathrm{av}} 2.6 \mathrm{~nm}$. This result is consistent with the TEM result.

Fig. 1(c) illustrates the XRD pattern of $\mathrm{ZnS}: \mathrm{Mn}^{2+}$ nano-particles. The pattern showed peak from (111), (220) and (311) planes, indicating the formation of cubic phase, in agreement with the electron diffraction results. Broadening of the XRD peaks can be attributed to the small size of the $\mathrm{ZnS}: \mathrm{Mn}^{2+}$ nano-particles present in the sample. The crystallite size was obtained as $3.02 \mathrm{~nm}$ from the XRD data using the Debye equation. This value tallied well with the TEM and PSA results as mentioned earlier.

\subsection{Characterization of the surface of $\mathrm{ZnS}: \mathrm{Mn}^{2+}$ nano-particles}

For understanding the adsorption mechanism of the 2ethylhexanoic acid on the surface, FTIR analysis of $\mathrm{ZnS}: \mathrm{Mn}^{2+}$ nano-particles capped with 2-ethylhexanoic acid were carried out
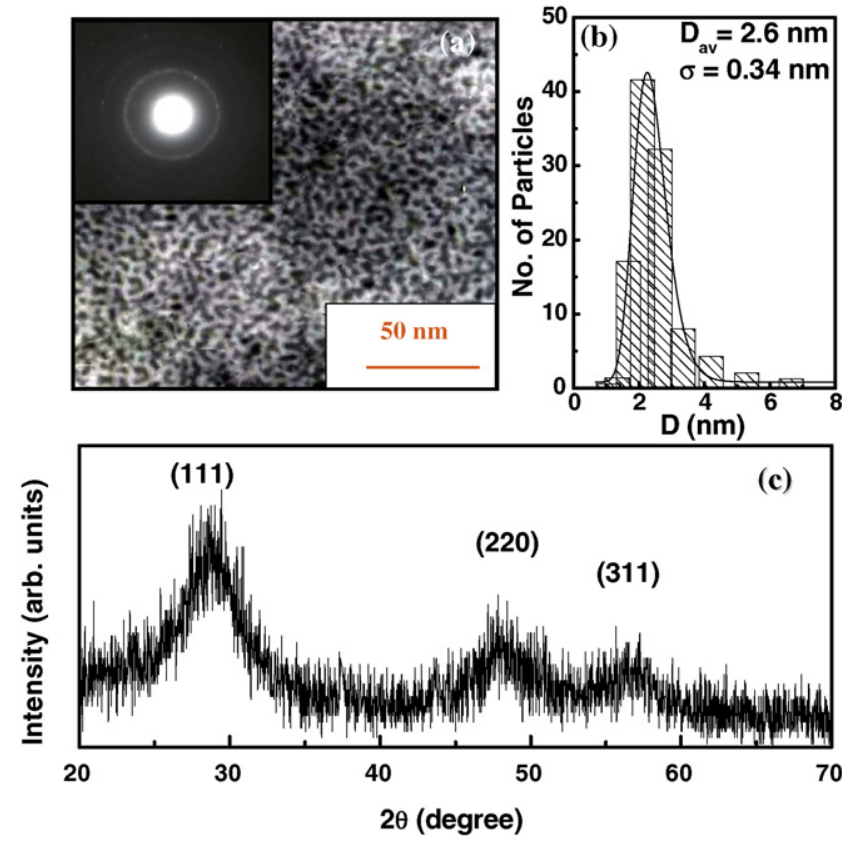

Fig. 1. (a) Transmission electron micrograph (TEM) with corresponding electron diffraction pattern, (b) particle size analysis data and (c) powder X-ray diffraction pattern of 2-ethylhexanoic acid coated $\mathrm{ZnS}: \mathrm{Mn}^{2+}$ nano-particles prepared using $200 \mathrm{~W}$ microwave power.

and the obtained data were compared to the IR spectrum of the pure 2-ethylhexanoic acid (Fig. 2a). The peak assignments for 2ethylhexanoic acid are listed in Table 1 [18]. The broad feature between 3500 and $2500 \mathrm{~cm}^{-1}$ were assigned to the $\mathrm{O}-\mathrm{H}$ stretch of the carboxylic acid. Two sharp bands at 2951 and $2868 \mathrm{~cm}^{-1}$, which were superimposed on the $\mathrm{O}-\mathrm{H}$ stretch, were attributed to the asymmetric $\mathrm{CH}_{2}$ stretch and the symmetric $\mathrm{CH}_{2}$ stretch, respectively. The intense peak at $1697 \mathrm{~cm}^{-1}$ was derived from the existence of the $\mathrm{C}=\mathrm{O}$ stretch and the band at $1276 \mathrm{~cm}^{-1}$ exhibited the presence of the $\mathrm{C}-\mathrm{O}$ stretch [18]. The $\mathrm{O}-\mathrm{H}$ in-plane and out-of-plane bands appeared at 1458 and $938 \mathrm{~cm}^{-1}$, respectively.

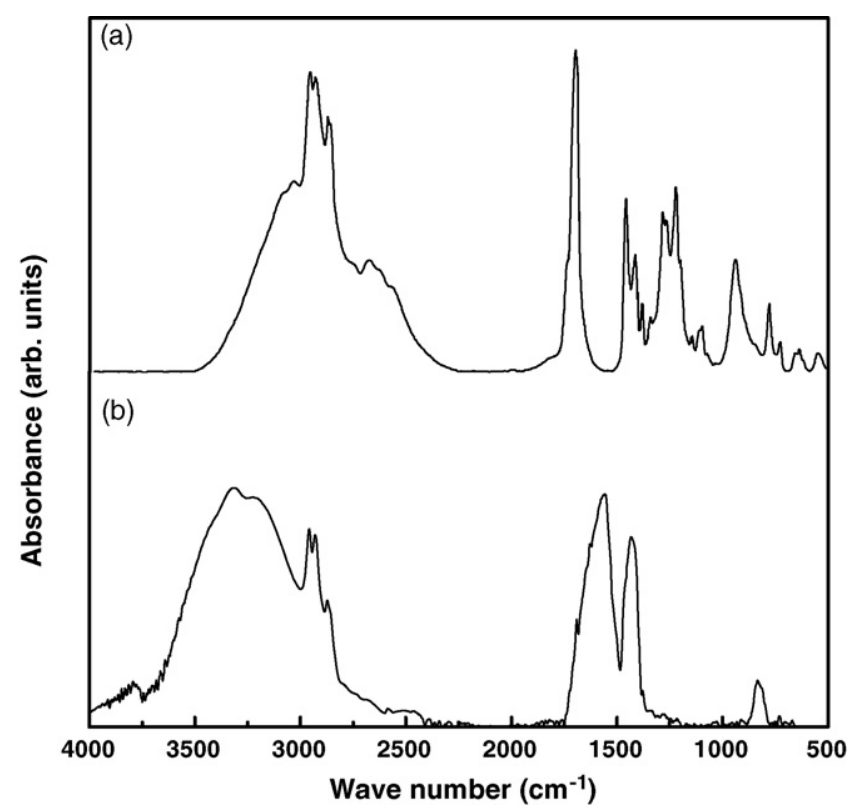

Fig. 2. FTIR spectra of (a) 2-ethylhexanoic acid and (b) 2-ethylhexanoic acid coated $\mathrm{ZnS}: \mathrm{Mn}^{2+}$ nano-particles prepared using $200 \mathrm{~W}$ microwave power. 
Table 1

Assignments of vibrational mode for 2-ethylhexanoic acid

\begin{tabular}{ll}
\hline Peak $\left(\mathrm{cm}^{-1}\right)$ & Assignment \\
\hline $3400-2400$ & O-H stretch \\
2951 & Asymmetric $\mathrm{CH}_{2}$ stretch \\
2868 & Symmetric $\mathrm{CH}_{2}$ stretch \\
1697 & $\mathrm{C}=\mathrm{O}$ stretch \\
1458 & In plane O-H stretch \\
1276 & C-O stretch \\
938 & Out-of-plane O-H stretch \\
776 & $\mathrm{CH}_{2}$ rocking \\
\hline
\end{tabular}

Fig. 2(b) reveals the IR spectrum obtained from the $\mathrm{ZnS}: \mathrm{Mn}^{2+}$ nano-particles coated with 2-ethylhexanoic acid. For the coated samples, the asymmetric $\mathrm{CH}_{2}$ stretch and the symmetric $\mathrm{CH}_{2}$ stretch shifted to 2947 and $2864 \mathrm{~cm}^{-1}$, respectively. Shifting of these bands to the lower frequencies could be attributed to the partial bond formation with the surface $\mathrm{Zn}$ atoms which eventually passivate the surface of $\mathrm{ZnS}: \mathrm{Mn}^{2+}$ nano-particles. It is worth noting that the $\mathrm{C}=\mathrm{O}$ stretch band of the carboxyl group, which is present at $1697 \mathrm{~cm}^{-1}$ in the IR spectrum of pure 2-ethylhexanoic acid, is absent in the spectrum of the coated $\mathrm{ZnS}: \mathrm{Mn}^{2+}$ nano-particles. Instead, two new bands at 1561 and $1427 \mathrm{~cm}^{-1}$ are characteristic of the asymmetric $v_{\text {as }}\left(\mathrm{COO}^{-}\right)$and the symmetric $v_{\mathrm{s}}\left(\mathrm{COO}^{-}\right)$stretch [18]. This reveals that 2-ethylhexanoic acid is chemisorbed as a carboxylate onto the $\mathrm{ZnS}: \mathrm{Mn}^{2+}$ nano-particles, and the two oxygen atoms in the carboxylate are coordinated symmetrically to the $\mathrm{Zn}$ atoms.

Based upon previous studies of carboxylates [19,20], the interaction between the carboxylate head and the metal atom is categorized as four types: monodentate, bridging bidentate, chelating bidentate, and ionic interaction. The wave number separation, $\Delta$, between the $v_{\text {as }}\left(\mathrm{COO}^{-}\right)$and $v_{\mathrm{s}}\left(\mathrm{COO}^{-}\right)$IR bands can be used to diagnose the type of the interaction between the carboxylate head and the metal atom. The largest $\Delta\left(200-320 \mathrm{~cm}^{-1}\right)$ corresponds to the monodentate interaction and the smallest $\Delta\left(<110 \mathrm{~cm}^{-1}\right)$ for the chelating bidentate. The medium range $\Delta\left(130-190 \mathrm{~cm}^{-1}\right)$ is for the bridging bidentate. In this work, the $\Delta\left(1561-1427=134 \mathrm{~cm}^{-1}\right)$ is ascribed to the bridging bidentate, where the interaction between the $\mathrm{RCOO}^{-}$group and the $\mathrm{Zn}$ atom is covalent.

To further examine the chemical structure of the surface coated $\mathrm{ZnS}: \mathrm{Mn}^{2+}$ nano-particles, the XPS spectra of $\mathrm{C} 1 \mathrm{~s}, \mathrm{O} 1 \mathrm{~s}$, and $\mathrm{Zn} 2 \mathrm{p}$ core levels were obtained. Two $C 1$ s peaks appearing at 284.7 and $288.2 \mathrm{eV}$ (Fig. 3(a)) are ascribed to the carbon atoms in the aliphatic chain $(\mathrm{C}-\mathrm{C})$ and the carboxylate $\left(-\mathrm{COO}^{-}\right)$, respectively, which is consistent with the data obtained from carboxylates in the previous literature $[21,22]$. No $\mathrm{C} 1 \mathrm{~s}$ peak corresponding to carboxylic carbon $(-\mathrm{COOH})$ appeared in the spectrum, indicating the absence of free acid on the coated $\mathrm{ZnS}: \mathrm{Mn}^{2+}$ nano-particles. This is also confirmed by the $\mathrm{O} 1 \mathrm{~s}$ peak feature at $531.5 \mathrm{eV}$ (Fig. 3(b)). A single and symmetrical $\mathrm{O} 1 \mathrm{~s}$ peak reveals the presence of two symmetrical oxygen atoms in the carboxylate $\left(\mathrm{COO}^{-}\right)$moiety and the absence of the $\mathrm{C}=\mathrm{O}$ bond in the coated nano-particles. The $\mathrm{Zn} 2 \mathrm{p}$ doublet was further deconvoluted and the results are shown in Fig. 4. Peaks corresponding to the binding energies of 1021.8 and $1045.1 \mathrm{eV}$ imply the $\mathrm{Zn}-\mathrm{O}$ bond formation in the carboxylate, while the deconvoluted peaks of the $\mathrm{Zn} 2 \mathrm{p}$ doublet with binding energies of 1022.2 and $1046.2 \mathrm{eV}$ correspond to the $\mathrm{Zn}-\mathrm{S}$ bond in the $\mathrm{ZnS}: \mathrm{Mn}^{2+}$ nano-particles [23].

It is known [24-26] that bonding types of carboxylate groups to the metal atoms may be either a bidentate bond through two equivalent oxygen atoms or a monodentate bond with inequivalent oxygen atoms. In the case of the monodentate bond, the $\mathrm{C}=\mathrm{O}$ bond is still present and the acid hydrogen is substituted by metal atoms. In the above case, the IR spectrum should show a strong band at $1700-1730 \mathrm{~cm}^{-1}$ and the $01 \mathrm{~s}$ XPS spectrum should display
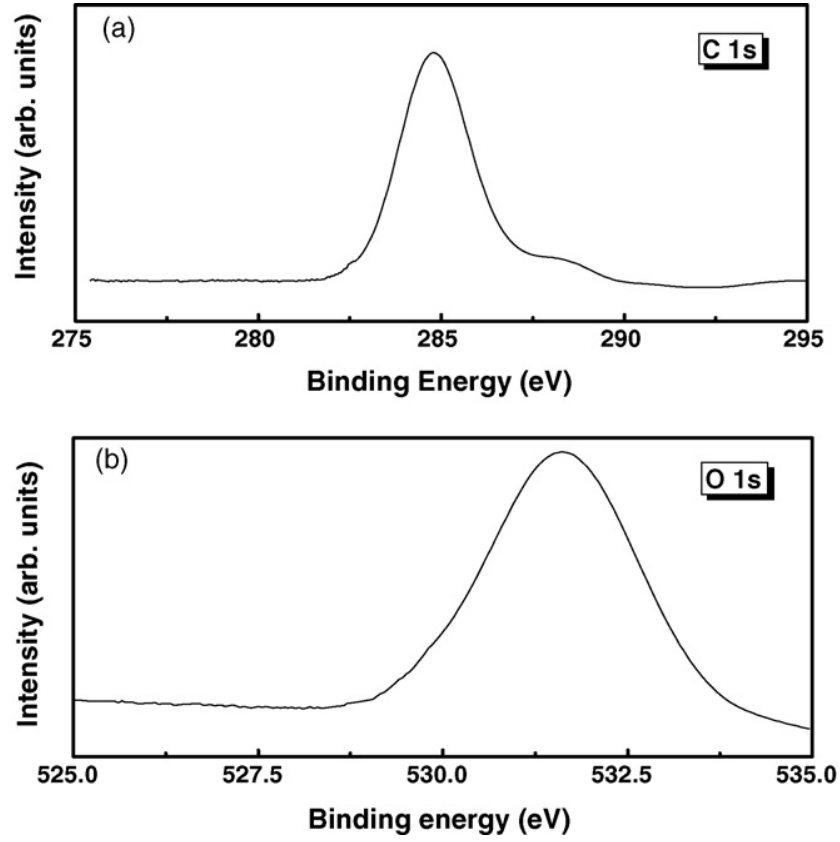

Fig. 3. XPS spectra for C 1s (a) and O 1s (b) levels in 2-ethylhexanoic acid coated $\mathrm{ZnS}: \mathrm{Mn}^{2+}$ nano-particles prepared using $200 \mathrm{~W}$ microwave power.

another peak at around $533 \mathrm{eV}$ in addition to the first one around $531 \mathrm{eV}$. This study demonstrates that the IR band at $1697 \mathrm{~cm}^{-1}$ disappears after the 2-ethylhexanoic acid has been adsorbed on the surface of the $\mathrm{ZnS}$ nano-particles. In addition, the $01 \mathrm{~s}$ XPS spectrum that was obtained from the coated $\mathrm{ZnS}$ nano-particles illustrates a single peak instead of two nonequivalent peaks. Therefore, it can be inferred that carboxylate groups are bound to the $\mathrm{Zn}$ atoms symmetrically through its two oxygen atoms at surface.

Based on the obtained results, it was found that the microwave irradiation during the heating process provides energy to produce free $\mathrm{Zn}^{2+}$ ions from zinc 2-ethylhhexanoate, required for $\mathrm{ZnS}$ synthesis. From the rest part of the precursor, 2-ethylhexanoic acid is produced and chemisorbed as carboxylate onto the surface of

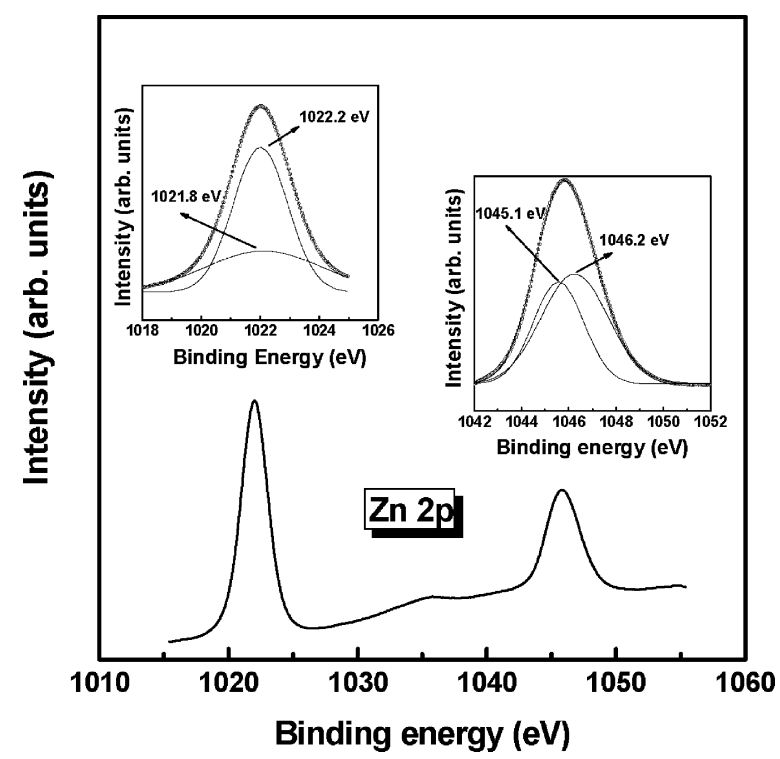

Fig. 4. XPS spectra for $\mathrm{Zn} 2 \mathrm{p}$ levels in 2-ethylhexanoic acid coated $\mathrm{ZnS}: \mathrm{Mn}^{2+}$ nanoparticles prepared using $200 \mathrm{~W}$ microwave power. Inset shows the deconvulation of each peak of the $\mathrm{Zn} 2 \mathrm{p}$ doublet. 


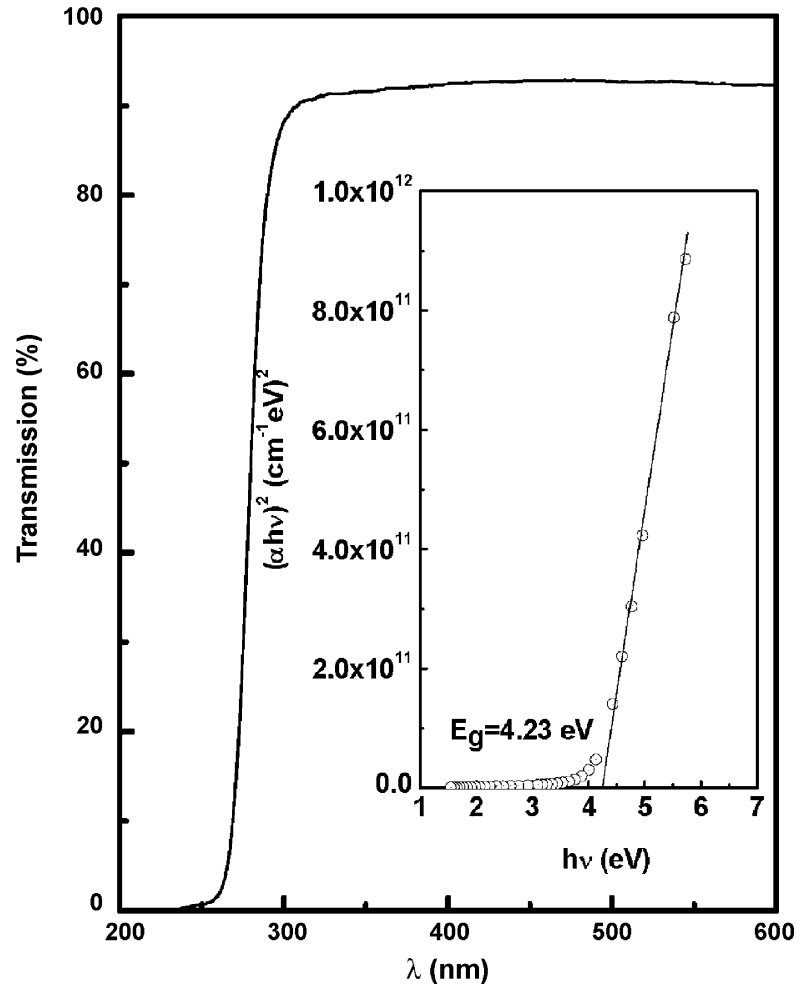

Fig. 5. Optical transmission spectrum of 2-ethylhexanoic acid coated $\mathrm{ZnS}: \mathrm{Mn}^{2+}$ nano-particles prepared using $200 \mathrm{~W}$ microwave power. Inset shows the $(\alpha h \nu)^{2} \mathrm{vs}$. $h v$ plot for determining the bandgap of the sample.

$\mathrm{ZnS}: \mathrm{Mn}^{2+}$ nano-particles and the two oxygen atoms in the carboxylate are coordinated symmetrically to the $\mathrm{Zn}$ atoms, leading to the formation of the covalent $\mathrm{Zn}-\mathrm{O}$ bond. The anion bound onto the nano-particle surface prevents particle agglomeration due to electrostatic repulsion between two adjacent particles.

\subsection{Optical and photoluminescence study of $\mathrm{ZnS}: \mathrm{Mn}^{2+}$ nano-particles}

Fig. 5 shows the transmittance $(T)$ as a function of the wavelength $(\lambda)$ recorded in the $\lambda$ region, ranging from 200 to $600 \mathrm{~nm}$. The sharp fall in the $T$ value at lower wavelengths is associated with the excitonic optical transition in $\mathrm{ZnS}: \mathrm{Mn}^{2+}$ nano-crystallites. The exact band gap value was obtained using the conventional method, extrapolating the straight line portion of the $(\alpha h v)^{2}$ vs. $h v$ plot to $\alpha=0$. The $E_{\mathrm{g}}$ value obtained $(4.23 \mathrm{eV})$ for the sample synthesized at a microwave power of $200 \mathrm{~W}$ was greater than that of the $E_{\mathrm{g}}$ value of the bulk $\mathrm{ZnS}(3.68 \mathrm{eV})$ [27]. The blue shift in the band gap is attributed to the quantum size effect due to smaller crystallite size. The nano-crystalline material properties show a deviation from the corresponding bulk properties when the crystallite sizes become comparable to the Bohr excitonic radius $\left(a_{\mathrm{B}}\right), 2.5 \mathrm{~nm}$ for $\mathrm{ZnS}$. The particle radius value in the nano-crystalline $\mathrm{ZnS}: \mathrm{Mn}^{2+}$, as determined from TEM studies, is smaller than $a_{\mathrm{B}}$ supporting the strong quantum-size effect in the $\mathrm{ZnS}: \mathrm{Mn}^{2+}$ powder. Further, the blue shift in the band gap $\left(\Delta E_{\mathrm{g}}\right)$ could also be utilized to determine the crystallite radius $(r)$ using the following relation [28]:

$\Delta E_{\mathrm{g}}=E_{\mathrm{g}}($ powder $)-E_{\mathrm{g}}($ bulk $)=\left[\frac{h^{2} \pi^{2}}{2 \mu r^{2}}\right]-\left[\frac{1.8 e^{2}}{\varepsilon r}\right]$

where $\mu$ is the reduced electron-hole effective mass. Using the $\varepsilon=8.76, m_{e}^{*}=0.34 m_{0}$ and $m_{h}^{*}=0.23 m_{0}$ values, assuming spherical crystallites, the particle size was determined as $2.87 \mathrm{~nm}$. This

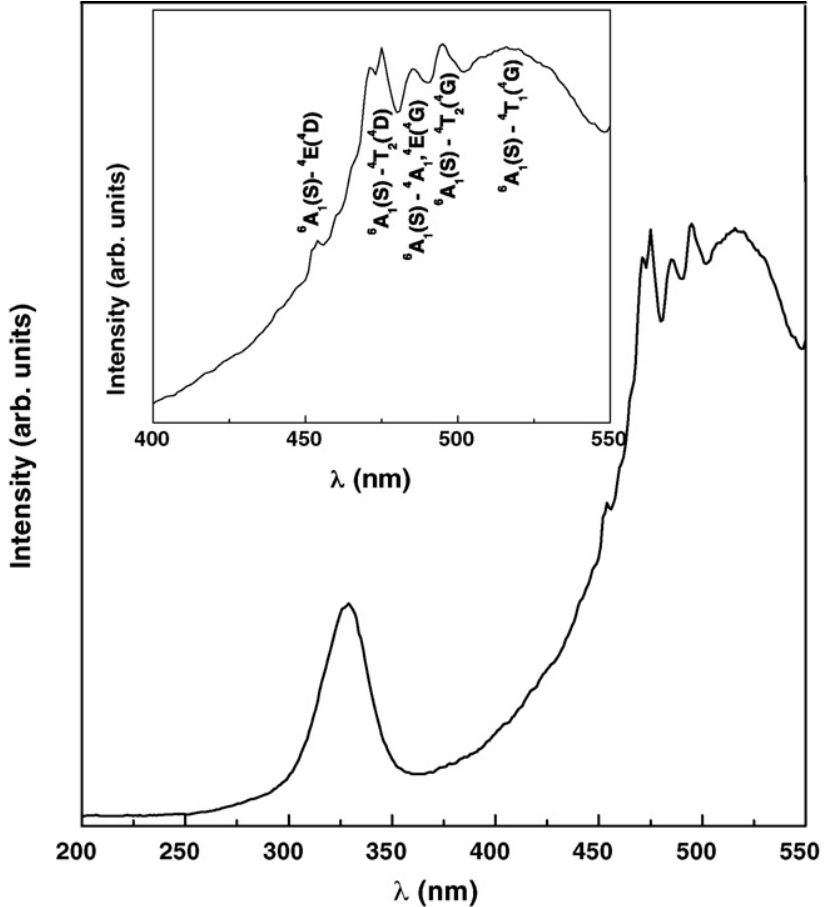

Fig. 6. PL excitation spectrum of 2-ethylhexanoic acid coated $\mathrm{ZnS}: \mathrm{Mn}^{2+}$ nano particles prepared using $200 \mathrm{~W}$ microwave power. Inset shows the fine structure in the spectrum at the wavelength region $400-550 \mathrm{~nm}$.

value is comparable to those obtained from TEM, PSA or XRD studies.

The $\mathrm{d}-\mathrm{d}$ transitions of $\mathrm{Mn}^{2+}$ ions in $\mathrm{ZnS}$ nano-particles are observed in the PLE spectrum for the sample synthesized with $200 \mathrm{~W}$ microwave power. The spectrum shows fine structure having five absorption peaks in the wave length region of $400-550 \mathrm{~nm}$ (Fig. 6 (inset)). These peaks occurred at 453, 474, 485, 495 and $517 \mathrm{~nm}$ in addition to the main peak at $324 \mathrm{~nm}$. Chen et al. [29] also reported similar observation of the existence of five absorption bands in the PLE spectra of $\mathrm{ZnS}: \mathrm{Mn}^{2+}$ nano-particles in the cavities of zeolite-Y, prepared by solid state diffusion at high temperature. Compared to the $\mathrm{Mn}^{2+}$ PLE spectra of bulk $\mathrm{ZnS}: \mathrm{Mn}^{2+}[30-32]$ it is known that the five absorption bands are due to the ${ }^{6} A_{1}(S) \rightarrow{ }^{4} \mathrm{E}$ $\left({ }^{4} \mathrm{D}\right),{ }^{6} \mathrm{~A}_{1}(\mathrm{~S}) \rightarrow{ }^{4} \mathrm{~T}_{2}\left({ }^{4} \mathrm{D}\right),{ }^{6} \mathrm{~A}_{1}(\mathrm{~S}) \rightarrow{ }^{4} \mathrm{~A}_{1},{ }^{4} \mathrm{E}\left({ }^{4} \mathrm{G}\right),{ }^{6} \mathrm{~A}_{1}(\mathrm{~S}) \rightarrow{ }^{4} \mathrm{~T}_{2}\left({ }^{4} \mathrm{G}\right)$, and ${ }^{6} A_{1}(S) \rightarrow{ }^{4} T_{1}\left({ }^{4} G\right)$ transitions, respectively.

The excitation spectra of $\mathrm{Mn}^{2+}$ in $\mathrm{ZnS}: \mathrm{Mn}^{2+}$ nano-particles were reported by Tanaka et al. [33] observing bands at 465, 497 and $529 \mathrm{~nm}$, respectively. In the present study, the observed five excitation bands and the wavelengths of the corresponding three bands $\left[{ }^{6} \mathrm{~A}_{1}(\mathrm{~S}) \rightarrow{ }^{4} \mathrm{~A}_{1},{ }^{4} \mathrm{E}\left({ }^{4} \mathrm{G}\right),{ }^{6} \mathrm{~A}_{1}(\mathrm{~S}) \rightarrow{ }^{4} \mathrm{~T}_{2}\left({ }^{4} \mathrm{G}\right)\right.$ and $\left.{ }^{6} \mathrm{~A}_{1}(\mathrm{~S}) \rightarrow{ }^{4} \mathrm{~T}_{1}\left({ }^{4} \mathrm{G}\right)\right]$ are a few nanometers shifted from the reported observations [33]. This observation can be attributed to the difference in the local structures around $\mathrm{Mn}^{2+}$ luminescent centers in $\mathrm{ZnS}: \mathrm{Mn}^{2+}$ nano-particles prepared using different synthesis techniques. These additional excitation peaks, other than the broad excitonic transition of $\mathrm{ZnS}$ are related to $\mathrm{Mn}^{2+}$ ions and can be attributed to the high-lying excited states of $\mathrm{Mn}^{2+}$ [31]. The energy levels of these higherexcited states of $\mathrm{Mn}^{2+}$ in $\mathrm{ZnS}$ have been calculated [31] and reported by measuring the transitions from the emitting state ${ }^{4} \mathrm{~T}_{1}\left({ }^{4} \mathrm{G}\right)$ of $\mathrm{Mn}^{2+}[31]$. The absorption coefficients of the $\mathrm{d}-\mathrm{d}$ transitions are relatively small, since they are forbidden transitions [31]. As a result, it is tough to measure the absorption of the transitions from the ground state to these high-lying states of $\mathrm{Mn}^{2+}$ in bulk $\mathrm{ZnS}: \mathrm{Mn}^{2+}$ as they are masked by the strong excitonic absorption of $\mathrm{ZnS}$ host [31]. In nano-particles, the absorption of the direct transitions from the 


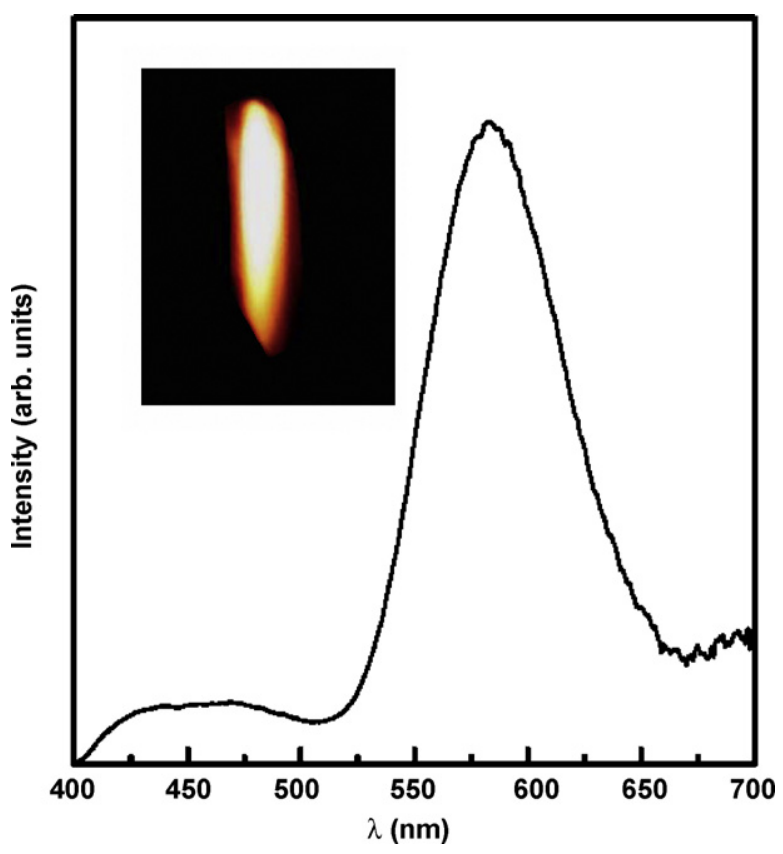

Fig. 7. $\mathrm{PL}$ emission spectrum of 2-ethylhexanoic acid coated $\mathrm{ZnS}: \mathrm{Mn}^{2+}$ nanoparticles prepared using $200 \mathrm{~W}$ microwave power. Inset shows the bright yellow-orange luminescence coming from the sample.

ground state to these high-lying states of $\mathrm{Mn}^{2+}$ is observed. This indicates that the $\mathrm{d}-\mathrm{d}$ transitions become allowed or partly allowed in case of nano-particles.

PL spectrum is recorded at room temperature and the result is shown in Fig. 7. The sample exhibits very bright yellow-orange luminescence at $585 \mathrm{~nm}$, characteristic of the ${ }^{4} \mathrm{~T}_{1}$ (excited) $\rightarrow{ }^{6} \mathrm{~A}_{1}$ (ground) transition of $\mathrm{Mn}^{2+}$ ion at $\mathrm{T}_{\mathrm{d}}$ symmetry in $\mathrm{ZnS}$ host. A weak and broad blue emission centered at about $440 \mathrm{~nm}$ also observed in addition to this bright yellow-orange emission. The weak peak at blue region can be attributed to the $\mathrm{S}^{2-}$ vacancies in the $\mathrm{ZnS}$ host [5]. Low intensity of this emission indicates better surface passivation of the $\mathrm{ZnS}: \mathrm{Mn}^{2+}$ nano-particles in the present study. It is found that the emission peak at $585 \mathrm{~nm}$ is broad in nature. The broadness of this emission band occurs due to the combination of inhomogeneous broadening and phonon assisted transition [34]. Longitudinal (LO and LA) and transverse (TO and TA) optical and acoustic phonons are not resolvable at room temperature [35].

It was reported [36] that in $\mathrm{Mn}^{2+}$ activated $\mathrm{ZnS}$ nano-crystals in which the $\mathrm{Mn}^{2+}$ ions are distributed outside the $\mathrm{ZnS}$ nano-crystals, the PL emission is totally different from that of $\mathrm{Mn}^{2+}$-doped $\mathrm{ZnS}$ nano-crystals in which the $\mathrm{Mn}^{2+}$ is incorporated within the nanocrystals. When the $\mathrm{Mn}^{2+}$ is incorporated within the crystals, both the $435 \mathrm{~nm}$ blue emission of $\mathrm{ZnS}$ and the orange $\mathrm{Mn}^{2+}$ emission at $590 \mathrm{~nm}$ are observed. However, in the $\mathrm{Mn}^{2+}$ activated $\mathrm{ZnS}$ nanocrystals in which the $\mathrm{Mn}^{2+}$ ions are distributed outside the $\mathrm{ZnS}$ crystals, no orange emission at $590 \mathrm{~nm}$ is observed, a new peak at $350 \mathrm{~nm}$ appears, and the blue $435 \mathrm{~nm}$ emission in $\mathrm{ZnS}$ is considerably quenched and shifted to $390 \mathrm{~nm}$. Comparison of these observations with the results of the present study suggests that in this case, the $\mathrm{Mn}^{2+}$ ions are incorporated within the $\mathrm{ZnS}$ nanoparticles. The bright yellow orange emission from the sample is shown in the inset of Fig. 7.

\subsection{ESR study of $\mathrm{ZnS}: \mathrm{Mn}^{2+}$ nano-particles}

The symmetry, electronic structure and coordination states of $\mathrm{Mn}$ impurity in $\mathrm{ZnS}: \mathrm{Mn}^{2+}$ powder and thin films have been stud-

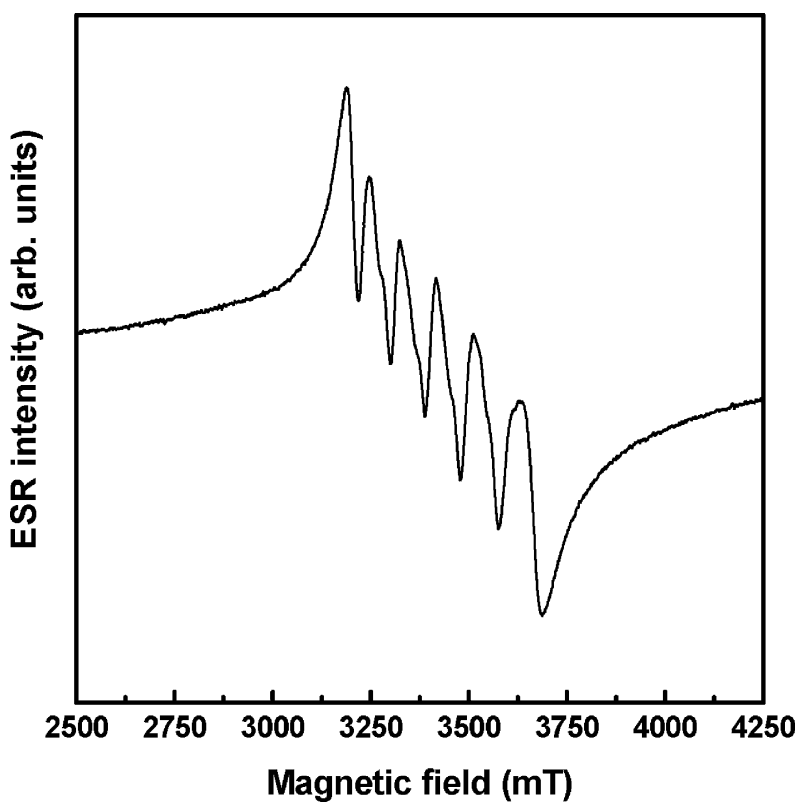

Fig. 8. ESR spectrum of 2-ethylhexanoic acid coated $\mathrm{ZnS}: \mathrm{Mn}^{2+}$ nano-particles prepared using $200 \mathrm{~W}$ microwave power.

ied by different workers [37,38] using ESR. The 2+ charge state of $\mathrm{Mn}$ has a half-filled d-shell $\left(3 \mathrm{~d}^{5}\right)$ with angular momentum $L=0$ and spin $S=5 / 2$. The hyperfine structure results from the interaction between the nuclear spin of ${ }^{55} \mathrm{Mn}$ and its electronic spin. At low manganese-ion concentrations, a characteristic six line pattern of $\mathrm{Mn}^{2+}$ in the cubic $\mathrm{ZnS}$ lattice appears. In a cubic $\mathrm{ZnS}$ lattice containing substitutional $\mathrm{Mn}^{2+}$, hyperfine transitions are due to $\Delta M_{I}=0$, which gives rise to the characteristic six line spectrum.

Fig. 8 shows the ESR spectrum of $\mathrm{ZnS}: \mathrm{Mn}^{2+}$ nano-particles recorded using microwave power of $10 \mathrm{~mW}$ and modulation amplitude of $0.5 \mathrm{mT}$. The ESR parameters associated with the signal are $g=2.0009$ and hyperfine constant $|A|=88.9 \times 10^{-4} \mathrm{~cm}^{-1}$. Similar parameters were deduced by Kennedy et al. [37] for nano-sized Mn-doped ZnS powder $\left(g=2.001\right.$ and $\left.|A|=89 \times 10^{-4} \mathrm{~cm}^{-1}\right)$. The well-resolved resonance spectra consisting of six hyperfine lines revealed the fact that $\mathrm{Mn}^{2+}$ in $\mathrm{ZnS}$ was present as dispersed $\mathrm{Mn}^{2+}$ impurities rather than $\mathrm{Mn}^{2+}$ clusters, which would produce broad resonance without splitting. The ESR parameter values indicate that $\mathrm{Mn}^{2+}$ ions have replaced the $\mathrm{Zn}$ sites in the $\mathrm{ZnS}$ lattice [38].

\section{Conclusions}

Highly luminescent $\mathrm{ZnS}: \mathrm{Mn}^{2+}$ nano-particles were synthesized via a microwave irradiation technique using zinc 2-ethylhexanoate as a novel zinc precursor. This method was found to be an efficient technique for producing in situ capping of 2-ethylhexanoic acid on the surface of the $\mathrm{ZnS}: \mathrm{Mn}^{2+}$ nano-particles resulting enhanced luminescence intensity due to effective passivation. The anions bound on the surface of the nano-particles prevented particle agglomeration due to electrostatic repulsion between two adjacent particles. The nano-particles showed bright yellow-orange luminescence at about $585 \mathrm{~nm}$, characteristic of ${ }^{4} \mathrm{~T}_{1}$ (excited) $\rightarrow{ }^{6} \mathrm{~A}_{1}$ (ground) transition of $\mathrm{Mn}^{2+}$ ion at $\mathrm{T}_{\mathrm{d}}$ symmetry in $\mathrm{ZnS}$ crystals. ESR study showed a hyperfine sextet indicating the fact that $\mathrm{Mn}^{2+}$ in $\mathrm{ZnS}$ was present as dispersed $\mathrm{Mn}^{2+}$ impurities rather than $\mathrm{Mn}^{2+}$ clusters. 


\section{References}

[1] P.W. Cyr, M. Tzolov, M.A. Hines, I. Manners, E.H. Sargent, G.D. Scholes, J. Mater Chem. 13 (2003) 2213.

[2] J.H. Fendler, F.C. Meldrum, Adv. Mater. 7 (1995) 607.

[3] N. Lopez, T.V.W. Janssens, B.S. Clausen, Y. Xu, M. Mavrikakis, T. Bligaard, J.K. Norskov, J. Catal. 233 (2004) 232.

[4] A.P. Alivisatos, Science 271 (1996) 933.

[5] T. Ahmadi, Z.L. Wang, T.C. Green, A. Henglein, M.A. Elsayed, Science 272 (1996) 1924.

[6] D. Yelin, D. Oron, S. Thiberge, E. Moses, Y. Silberberg, Opt. Express 11 (2003) 1385.

[7] R.N. Bhargava, D. Gallagher, X. Hong, A. Nurmikko, Phys. Rev. Lett. 72 (1994) 416.

[8] X. Yu, L. Yang, S. Yang, P. Zhou, J. Mater. Res. 22 (2007) 1207.

[9] M. Wang, L. Sun, X. Fu, C. Liao, C. Yan, Solid State Commun. 115 (2000) 493.

[10] G. Sharma, S.D. Han, J.D. Kim, S.P. Khatkar, Y.W. Rhee, Mater. Sci. Eng. B 131 (2006) 271.

[11] T. Yamamoto, S. Kishimoto, S. Iida, Phys. Status Solidi B 229 (2002) 371.

[12] S.C. Ghosh, C. Thanachayanont, J. Dutta, Proceedings of the First ECTI Annual Conference (ECTI-CON 2004) 145 (2004).

[13] D. Gallagher, W.E. Heady, J.M. Racz, R.N. Bhargava, J. Mater. Res. 10 (1995) 870.

[14] I. Yu, T. Isobe, M. Senna, J. Phys. Chem. Solids 57 (1996) 373.

[15] O.A. Korotchenkov, A. Cantarero, A.P. Shpak, Y.A. Kunitskii, A.I. Senkevich, M.O. Borovoy, A.B. Nadtochii, Nanotechnology 16 (2005) 2033.

[16] R. Vacassy, S.M. Scholz, J. Dutta, C.J.G. Plummer, J. Am. Ceram. Soc. 81 (1998) 2699.

[17] S.M. Scholz, R. Vacassy, J. Dutta, H. Hofmann, M. Akinc, J. Appl. Phys. 83 (1998) 7860.
[18] B. Smith, Infrared Spectral Interpretation: A Systematic Approach, CRC Press, Boca Raton, 1999, 1999.

[19] K. Nakamoto, Infrared and Raman Spectra of Inorganic and Coordination Compounds, John Wiley \& Sons, New York, 1997, 1997.

[20] Y. Ren, K. Iimura, T. Kato, Langmuir 17 (2001) 2688.

[21] V.V. Korolev, A.G. Ramzanova, A.V. Blinov, Russ. Chem. Bull. 51 (2002) 2044

[22] E. Frydman, H. Cohen, R. Maoz, J. Sagiv, Langmuir 12 (1997) 5089.

[23] J.F. Moulder, W.F. Stickle, P.E. Sobol, K.D. Bomben, Handbook of X-ray Photoelectron Spectroscopy, Physical Electronics, Inc., MN, USA, 1995.

[24] L.H. Dubois, B.R. Zegarski, R.G. Nuzzo, Langmuir 2 (1986) 412.

[25] A. Vittadini, A. Selloni, F.P. Rotzinger, M. Grätzel, J. Phys. Chem. B 104 (2000) 1300.

[26] M. Wühn, J. Weckesser, C. Wöll, Langmuir 17 (2001) 7605

[27] Landolt-Bornstein: Numerical Data and Functional Relationships in Science and Technology, Springer-Verlag vol. 22a (1987) p. 167.

[28] Y. Kayanuma, Phys. Rev. B 38 (1998) 9797.

[29] W. Chen, R. Sammynaiken, Y. Huang, J.O. Malm, R. Wallenberg, J.O. Bovin, V. Zwiller, N.A. Kotov, J. Appl. Phys. 89 (2001) 1120.

[30] C. Benecke, H.E. Gumlich, Semiconductors and Semimetals, vol. 25, Academic, New York, 1988.

[31] R.A. Ford, E. Kauer, A. Rabenau, D.A. Brown, Ber. Bunsenges. Phys. Chem. 67 (1963) 460.

[32] T. Kushida, Y. Tanaka, Y. Oka, Solid state Commun. 14 (1974) 617.

[33] M. Tanaka, J.F. Qi, Y. Masumoto, J. Lumin. 87 (2000) 472.

[34] H.E. Gumlich, J. Lumin. 23 (1981) 73.

[35] P.D. Rack, P.H. Holloway, Mater. Sci. Eng. B 21 (1998) 171

[36] K. Sooklal, B.S. Cullum, S.M. Angel, C.J. Murphy, J. Phys. Chem. 100 (1996) 4551

[37] T.A. Kennedy, E.R. Glaser, P.B. Klein, R.N. Bhargava, Phys. Rev. B 52 (1995) 14356

[38] T. Igarashi, T. Isobe, M. Senna, Phys. Rev. B 56 (1997) 6444. 